CORRECTION

\title{
Correction: Use of the 22C3 anti-PD-L1 antibody to determine PD-L1 expression in multiple automated immunohistochemistry platforms
}

Marius Ilie, Shirin Khambata-Ford, Christiane Copie-Bergman, Lingkang Huang, Jonathan Juco, Veronique Hofman, Paul Hofman

Fig 1 is incorrect. The authors have provided a corrected version here.

\section{f open access}

Citation: Ilie M, Khambata-Ford S, Copie-Bergman C, Huang L, Juco J, Hofman V, et al. (2017) Correction: Use of the 22C3 anti-PD-L1 antibody to determine PD-L1 expression in multiple automated immunohistochemistry platforms. PLOS ONE 12 (10): e0186537. https://doi.org/10.1371/journal. pone. 0186537

Published: October 13, 2017

Copyright: @ 2017 llie et al. This is an open access article distributed under the terms of the Creative Commons Attribution License, which permits unrestricted use, distribution, and reproduction in any medium, provided the original author and source are credited. 


Dako ASL48

Tissue preparation

Sectioned at a thickness of $3 \mu \mathrm{m}$

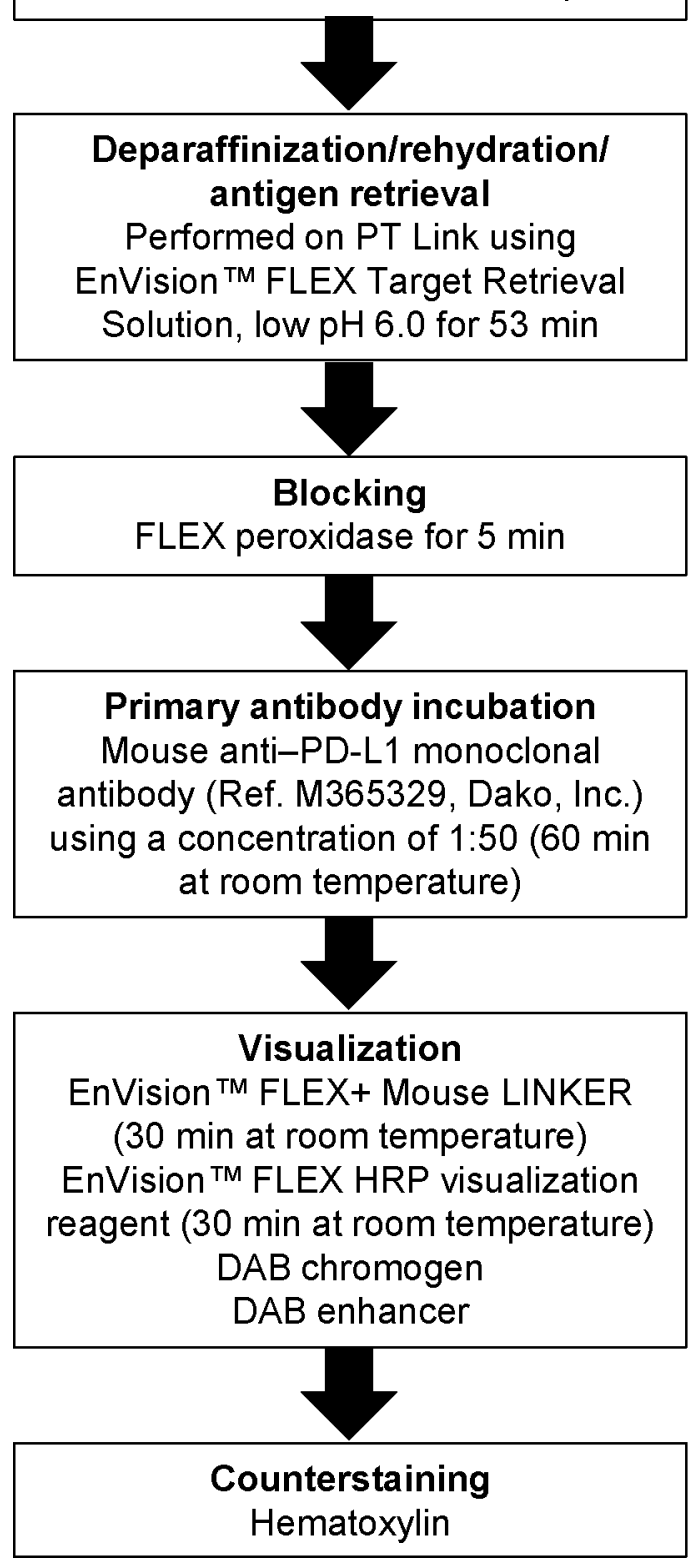

\section{Ventana ULTRA}

Tissue preparation

Sectioned at a thickness of $3 \mu \mathrm{m}$

Deparaffinization/rehydration/ antigen retrieval

$\mathrm{CC} 1$ (prediluted; $\mathrm{pH} 8.0$ ) antigen retrieval solution (Ventana) performed on the BenchMark ULTRA automated slide stainer (Ventana) for $64 \mathrm{~min}$ at $100^{\circ} \mathrm{C}$

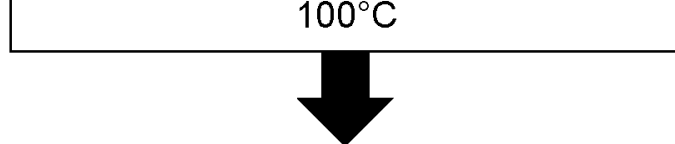

Primary antibody incubation

Mouse anti-PD-L1 monoclonal antibody (Ref. M365329, Dako, Inc.) using a concentration of 1:50 (32 min at $37^{\circ} \mathrm{C}$ )

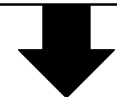

\section{Visualization}

OptiView DAB IHC Detection Kit + OptiView Amplification Kit (12 min)

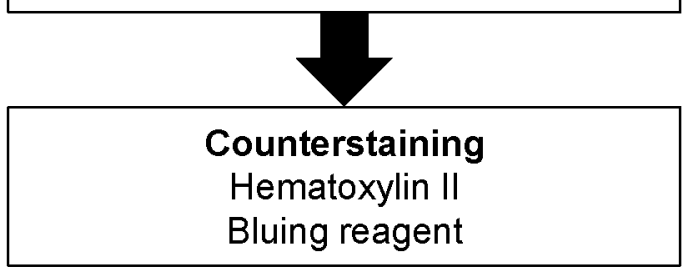

Fig 1. Optimised protocols for PD-L1 IHC assays using the $22 \mathrm{C} 3$ antibody concentrate on the Dako ASL48 and VENTANA BenchMark ULTRA platforms. PD-L1, programmed death ligand 1; IHC, immunohistochemistry; ASL48, Autostainer Link 48; DAB, 3,3'diaminobenzidine tetrahydrochloride.

https://doi.org/10.1371/journal.pone.0186537.g001

\section{Reference}

1. Ilie M, Khambata-Ford S, Copie-Bergman C, Huang L, Juco J, Hofman V, et al. (2017) Use of the 22C3 anti-PD-L1 antibody to determine PD-L1 expression in multiple automated immunohistochemistry platforms. PLoS ONE 12(8): e0183023. https://doi.org/10.1371/journal.pone.0183023 PMID: 28797130 